\title{
Le Moyen Âge à travers les âges
}

Alain Corbellari (2019).

Neuchâtel, Livreo-Alphil, 132 páginas. ISBN 978-2-88950-026-o.

Q Juan Manuel Lacalle

Universidad de Buenos Aires, Argentina

lacallejuanmanuel@gmail.com

Alain Corbellari, Profesor Extraordinario de Literatura Francesa Medieval en las Universidades de Neuchâtel y de Lausanne, nos ofrece en Le Moyen Âge à travers les âges un compendio abarcador del medievalismo, con especial acento en la literatura y en el ámbito francófonos. Su tesis, defendida en la Sorbonne en 1996 y publicada al año siguiente por Droz, pone de manifiesto su interés temprano por este enfoque novedoso, más ligado a la estética de la recepción: Joseph Bédier: écrivain et philologue. Otras de sus publicaciones destacadas son Des fabliaux et des hommes (2015) y Prismes de l'amour courtois (2018).

El libro cuenta con una introducción, "Quel(s) Moyen(s) Âge(s)?", una conclusión titulada “Le Moyen Âge aujourd'hui" y nueve capítulos con subapartados que, en su mayoría, realizan un recorrido cronológico y juegan con dos polos autorales. Su mención resulta bastante ilustrativa del itinerario que se nos propone: "Le Moyen Âge par lui-même - De Chrétien de Troyes à Pierre Sala", "Le Moyen Âge refoulé - De Pétrarque à Voltaire", "Le Moyen Âge contre les Lumières - De Fauchet à Stendhal", "Le Moyen Âge rose et noir des romantiques - De Walpole à Flaubert", "Le Moyen Âge érudit - De Bodmer à Bédier", "Le Moyen Âge idéalisé - De Bloy à Aragon", "Le Moyen Âge suspecté - De Twain à Kristeva”, "Le Moyen Âge réhabilité - De Zumthor à George R.R. Martin”, “Un exemple de réception moderne: le Moyen Âge en BD - De Prince Valiant à Kaamelott". La sucesión que se repasa busca dejar en evidencia cómo la distancia entre lo medieval y nuestra cotidianeidad se fue reduciendo. Este movimiento se agudiza ante la consideración de que la Edad Media es una época lo sufcientemente lejana y cercana, al mismo tiempo un nosotros y lo otro: "Il fournit l'occasion rêvée de nous voir nous-mêmes dans une autre peau" (10).

El puntapié para el trayecto es una cita del escritor suizo contemporáneo Jacques Chessex, que contempla una imagen positiva de la Edad Media. Al margen de esta apreciación, esto sirve para ilustrar la omnipresencia de la época medieval en nuestros días y, paralelamente, el crecimiento del medievalismo como disciplina desde los años 70 (en un primer momento, en los países germánicos y anglosajones). Corbellari discute el uso confuso del término "medievalismo", acuñado por Studies in Medievalism desde su primer número de 1979, dado que designaría las producciones y los usos modernos de la Edad Media así como, también, el estudio de esos usos. Por este motivo, este autor plantea, en cambio, la conceptualización de "recepción medieval". En Francia, de hecho, la asociación que acoge este tipo de estudios, fundada en 2004, se aleja del término hoy más usual y lleva por nombre Modernités médiévales.

Por su parte, la crítica francesa, profundiza y focaliza Corbellari, se ha interesado tardíamente por los fenómenos denominados rémanences (por ejemplo, recién en 1997 tuvo lugar el primer congreso de estudios francófonos sobre la temática). Además, apunta, en el caso francés los estudios de recepción son aún más nacionalistas y se apoyan en reflexiones identitarias. No obstante el punto de vista francófono sobre la producción, se destaca la importancia de reparar en los imaginarios de otras culturas europeas medievales ya que la influencia es recíproca. Esto mismo es lo que genera que muchos de los especialistas en medievalismo provengan del área de las literaturas comparadas o tomen ese marco metodológico.

Antes de abordar el corpus, y a modo de alerta para quienes deseen realizar análisis similares, se resalta el cuidado con la trampa de juzgar el pasado medieval a través de nuestro presente y la suma importancia de conocer el medioevo para trabajar adecuadamente con las producciones medievalistas. Como cierre de la introducción, Corbellari recuerda las nueve hipóstasis modernas que menciona Umberto Eco en Il costume di casa; la Edad Media como o vinculada con: pretexto, lugar de visita irónica, época bárbara, romanticismo, philosophia perennis, identidades nacionales, decadencia, reconstrucción filológica, tradición. Más allá de la impresión borgeana que pueda dar esta enumeración, lo que esto enseña es la necesidad de comprender nuestra fascinación por lo medieval y las diferentes imágenes que nos formamos de la Edad Media. Corbellari apuesta a privilegiar 
la visión profana frente a la científica, aunque reconoce que los eruditos juegan un rol muy importante en la evolución de la idea que nos hacemos de las épocas del pasado y la sucesión de actitudes hacia la Edad Media.

Uno de los primeros ejemplos de medievalismo que se pone en escena es la reescritura de Le Chevalier au Lion, de Chrétien de Troyes, por parte de Pierre Sala (1522), uno de los representantes de la llamada "poésie des ruines" que tendrá su punto de ebullición en el siglo XVIII. En el primer capítulo, se puntualiza al renacimiento como un fenómeno consustancial de la Edad Media, cuya serie concluye, por supuesto, en el siglo XVI. En esta primera parte se detallan las características primordiales de lo que luego será el germen de los diversos imaginarios, es decir, características políticas y culturales de la época medieval, y focos de emergencia literaria, con el epicentro en el territorio anglonormando y la tierra de Oc entre 1050-1300 (22): la institución caballeresca y el código de honor; el amor cortés; las materias de Francia, Bretaña y Roma; la espiritualidad ligada al Graal y a los grandes predicadores (Bernardo de Claraval y Francisco de Asís); los fabliaux.

La variedad y la multiplicidad de estas peculiaridades acompañan la construcción de las denominadas Edad Media "rosa" y "negra"; esta última más ligada a elementos anteriores o posteriores al período central: la Inquisición; la magia o brujería; la peste; la violencia prefeudal; las invasiones; la barbarie. Precisamente, y a partir del racconto de las primeras polémicas y querellas literarias, Corbellari subraya el espíritu de "cambio en la continuidad" que delinearía toda la cultura medieval.

Los capítulos subsiguientes se adentran de lleno en el período moderno, partiendo de una primera etapa, aquí denominada “reprimida”, en que la Edad Media tendría un lugar más marginal y hasta prohibitivo. La fecha clave de la reevaluación moderna que se explicita es 1735, con el acontecimiento significativo de la reedición del Roman de la Rose (ausente desde 1538). Se trata del esplendor en Francia de empresas eruditas y de tiempos de anticuarios. Otros textos que se reeditan por esos años son los de Thibaut de Champagne, más cercano a una axiología reaccionaria opuesta a Voltaire y las luces, y los fabliaux. A fines del siglo XVIII, la Bibliothèque universelle des romans publica más de doscientos volúmenes vinculados a la tradición medieval.

Ya de lleno en el siglo XIX, y en ocasión del esplendor romántico, resulta insoslayable la producción inglesa.
Se presenta la novedad de una imagen mítica, sobre todo céltica, más que histórica, como sucede en autores como J. Macpherson. Un sitio preferencial tiene Walter Scott, no tanto por sus tres novelas medievalizantes, sino por su rol de erudito y editor de textos medievales y por la herencia que dejó a partir de su influencia. Por esta época, en el territorio francés se daba un apogeo y saturación del imaginario: Victor Hugo con su visión más histórica que literaria, óperas como La Muette de Portici (1828), el revival gótico arquitectónico o, por mencionar un hecho puntual, la creación en 1844 del actual Musée National du Moyen Âge. En este apartado se menciona y describe mucha producción medievalista, y se invita a conocer mucha otra, frente a la conciencia de proliferación imposible de enumerar; casi como una moda, se afirma. Sin embargo, toda esta abundancia no impide que ocurra algo que va a ser una constante en torno a los trabajos sobre medievalismo: en el prefacio a Mademoiselle de Maupin (1834), Théophile Gautier protesta contra una Edad Media que no se condice con la "verdadera". Esto se encuentra en consonancia, para ejemplificar, con la invención del estilo "medieval" por parte de Viollet-le-Duc y las numerosas restauraciones, como la de Carcassonne, que conllevan una manera creativa y no servil de reinterpretar el pasado. Aquí se destaca la concepción, muy propia de la Edad Media, de creación como recreación, como hace Joseph Bédier con su Roman de Tirstan et Iseus (1900), referencia nodal de las adaptaciones literarias medievales del siglo XX.

En el quinto capítulo se realiza un sucinto y muy detallado paneo por las escuelas filológicas de los siglos XVIII y XIX, especialmente la alemana y la francesa. Tras exponer algunos ejemplos de producciones contemporáneas a estos movimientos, como el Rienzi (1839), de Wagner, el texto se detiene en señalar el crisol de los nacionalismos como uno de los aspectos más problemáticos del "retorno de la Edad Media", puesto que muchas veces iría acompañado de discursos agresivos de exclusión. Esta atención al aspecto político e ideológico por parte de Corbellari no resulta una excepción y se cuela afortunadamente a lo largo de su producción.

Una nueva "edad de oro" del imaginario medieval se observa durante el período de entreguerras, aunque fundamentalmente a partir de un medievalismo tributario de la renovación del catolicismo en esa época (85), con la figura de Juana de Arco (canonizada en 1920) como eje heroico predilecto; desde una perspectiva política, está claro, se visualiza un giro más bien conservador. Se trata del pasaje de una visión nacionalista o patriótica, más propia de Michelet y la 
Tercera República, a otra más mística. Por otra parte, la Segunda Guerra Mundial polariza las contradicciones inherentes a la utilización artística e ideológica del imaginario medieval mediante el vínculo con el imaginario fascista (90). Por ende, tras la Segunda Guerra lo medieval sufre un eclipse por su falta de acción frente a la idea de modernidad y progreso, y debido a su perfil conservador. En paralelo, comienza a ganar terreno una visión más popular de la Edad Media:

S'ils sont quelque peu boudés par la grande littérature, les thèmes médiévaux continuent par contre de fleurir dans des genres plus populaires: la bande dessinée, le roman historique et le cinéma hollywoodien lui réservent une large place, mais dans une optique presque toujours idéalisante peu en phase avec les grands courants artistiques de l'époque (95).

Centrado en esta faceta novedosa, Corbellari realiza un muy completo paneo por producciones de estos géneros desde los años 50 en adelante. Uno de los textos mencionados es Les Rois maudits, de Druon, cuya crueldad anunciaría la renovación del imaginario medievalizante que tiene lugar en los años 70 (96). La medievalística de estos años sufre numerosos cambios: retroceso de las posiciones bédieristas frente al neotradicionalismo, renovación de los estudios celtas, irrupción de la nouvelle critique que implica el abordaje casi exclusivo de la literatura moderna y del canon clásico. En relación con esto último, Julia Kristeva ocupa un lugar singular, ya que en Le texte du roman, de 1970, trabaja con el Petit Jehan de Santré como la primera novela francesa escrita en prosa.

Conforme avanza la lectura nos vamos cerciorando de que hasta los años 70 del siglo XX predominaría un modelo de adaptación de la literatura medieval basado en el uso de una lengua con arcaísmos que remontan al siglo XVII; lo que crea la ilusión de una lengua que resulta, al mismo tiempo, otra y comprensible sin esfuerzos (81). Una de las hipótesis más presentes a lo largo del texto va tomando forma: a partir de los 70 se produce un crecimiento exponencial de la presencia de la Edad Media en las ficciones contemporáneas. "[L]a mise en question de l'axiologie qui avait dominé l'Occident depuis l'après-guerre a représenté pour le Moyen Âge une chance inespérée de retour, sinon de ces valeurs, du moins de son imaginaire" (100-1). En especial, El nombre de la rosa (1980) jugó un rol importante en la apertura al gran público; aunque en Francia debe destacarse la nueva novela histórica, tendencia representada por Jeanne Bourin y su La Chambre des dames (1979). En esta línea, Corbellari comenta distintos textos de fines del siglo XX y comienzos del XXI, en muchos casos de autores académicos, y los relaciona con un auge equivalente al del fantasy. Específicamente en el ámbito francófono, en los años 70 ocupa un rol preponderante la moda celta y, en el campo universitario, toma forma el medievalismo como disciplina (es significativo, por ejemplo, el Essai de poétique médiévale (1972), de Paul Zumthor). La creación de la Bibliothèque médiévale, con ediciones bilingües, testimonia la publicación de 41 títulos entre 1979-1997. Otras colecciones, hoy esenciales, son Lettres gothiques, desde 1989, y Champion Classiques, desde 2003. En continuidad con el ascenso del medievalismo, en los 90 crece la visibilidad de corrientes teóricas intrínsecamente vinculadas con la práctica medievalística, como la new philology, el new medievalism y la new codicology. Asimismo, y más recientemente, la filología medieval se ha posicionado como un terreno sumamente fecundo para la experimentación de las denominadas humanidades digitales.

En la actualidad, Corbellari distingue dos extremos opuestos en la utilización del imaginario medieval en la cultura moderna: "Ishiguro privilégie, dans le sillage de l'ancien Moyen Âge 'noir', une vision désenchantée, voir 'post-apocalyptique' (ou 'postfictionnelle', comme dirait Antoine Volodine) de son objet" (112). En otro orden, Roubaud, autor de Graal fiction (1978), en diálogo con la crítica universitaria, parte de un costado humorístico y de la interferencia de géneros y colisiones estilísticas:

Il gagne ainsi le pari de nous présenter la littérature médiévale comme la plus moderne qui soit et renouvelle le pari d'un Moyen Âge sinon toujours 'rose', du moins devenu éminemment ludique, et dont les pirouettes donnent la main à la fantasy et à un profond renouveau d'une littérature enfantine enfin dégagée des ornières moralisantes où elle était longtemps restée confinée (112).

Entre estos dos extremos se encuentran otros autores como Michon y Quignard.

El último capítulo del libro, a diferencia del resto, propone ejemplificar la recepción moderna del medioevo a partir de un género particular, la historieta, que reflejaría con particular transparencia las transformaciones del abordaje y la producción medievalista. Finalmente, en la conclusión, aparte de considerar algunas representaciones actuales de los usos del 
medievalismo, se resalta la fecundidad para el futuro y lo lejos que se está del agotamiento de este imaginario como disparador de nueva producción ficcional.

Si bien breve, Le Moyen Âge à travers les âges cumple en acompañar un recorrido por la recepción del imaginario medieval a lo largo del tiempo, con mayor detalle en Francia, y ofrece un amplio abanico de textualidades para adentrarse en este tipo de ficciones y poder cotejar las diferencias y las excepciones que se van señalando capítulo a capítulo. 